\title{
A REVIEW ON REACTIVE POWER MANAGEMENT IN
} POWER SYSTEM NETWORK

\author{
Ifra Nabi \\ Research Scholar \\ Department of Electrical Engineering \\ SSM College of Engineering \\ Parihaspora Pattan,J \& K, India
}

\begin{abstract}
The purpose of this review paper is to offer an examination of reactive power management in power system. Reactive power gives us the planning actions and operations requested for the improvement of voltage and voltage instability in power networks. This paper identifies the possible ways to reactive power compensation by voltage control to a specific level and improving stability of power system and increasing transmission capacity. The reactive power and steady state voltage in any distribution system could be appropriately managed by harmonizing the available voltage and reactive power control equipments. It begins with a survey of voltage stability and reactive power in the transmission, distribution and load, and the necessity of delivering the reactive power regionally. The illustrations of adopted managing properties of shunt power systems like Static VAR Compensator (SVC) - Static compensators of reactive power, STATCOM - type systems (static compensator), static reactive power generators and systems that combine both these solutions, which are indicated as SVC based on STATCOM were not overlooked.
\end{abstract}

KEYWORDS: Reactive power, voltage control, voltage stability, SVC, STATCOM, voltage collapse.

\section{INTRODUCTION}

In the power system operation, control of reactive power and voltage is a major issue. This is due to the topological dissimilarities among the transmission and distribution systems, different approaches have improved. This review paper comprises of the offerings of the voltage stability and novel reactive power techniques for transmission and distribution systems. A strong emphasis is made in the expansion of the control methods to avert voltage collapse that can lead to extensive outrages. So, for the purpose of attaining systematic and dependable operation of power system, the control of reactive power and voltage shall please the given purposes:-

\author{
${ }^{1}$ Ishtiyaq Shafi Rafiqi,${ }^{2}$ Adfar Majid\& ${ }^{3}$ Arshid Ali \\ ${ }^{1 \& 2}$ Associate Professor, ${ }^{3}$ Assistant Professor \\ Department of Electrical Engineering \\ SSM College of Engineering \\ Parihaspora Pattan,J \& K, India
}

- Voltages at all the designated ends of all the equipments in the system are not beyond a sustainable range.

- The stability of the system is intensified to boost the usage of transmission system.

- The flow of reactive power is reduced in order to lessen the $\mathrm{I}^{2} \mathrm{R}$ and $\mathrm{I}^{2} \mathrm{X}$ losses.

This certifies that the transmission system runs mostly on real power. So, when the power system is supplying power to numerous loads and is sustaining from a number of production units, there arises the complication of keeping the voltage in permissible range. Since the load in any power system vary, the reactive power necessities of the transmission system vary. As it is not possible to transfer or transport the reactive power over longer distances, the voltage control is affected by the use of special devices placed across the system that owns troubles in maintaining adequate quantity of voltage and reactive power in the power system network. Practically, aforementioned has been happening from the time primary power system was set up. Growing demands considering both the quality of supplied power and supply reliability, force using increased the advanced devices. So, among the various provocations of power system engineering, the genuine preference and harmonization of equipments for maintaining or controlling the voltage stability and reactive power are a major challenge. These challenges led to the use of some selected devices for maintaining or controlling the reactive power. So, to keep up with the increasing demand of reactive power and voltage stability not beyond the desired range, some sources of reactive power like SVC-static compensator of reactive power, STATCOM-type system, static reactive power generators and system that merge these two solutions, which are indicated as SVC based on STATCOM. In past few decades, notable progress has been made concerning the equipments that are planned to enhance the voltage stability in power system. This is mostly because of the evolution of power system which needs pursuing more efficient ways of controlling and adjusting the power flows and voltage levels. Power supply system produces and consumes two types of powers: Real power (also known as active power) and Reactive power. Active power is the true power dished out to any load and the useful work is accomplished by it. On the 
other hand, Reactive power is used for system reliability as it aids the voltage that has to be managed. Reactive power doesn't do any useful work; it is required for moving active or real power via transmission and distribution systems to consumers. In AC systems, voltage and currents palpitate at alike frequency. Even though voltage and currents pulsate at the frequency in an $\mathrm{AC}$ system, they attain the highest points at distinct times.

Power is equal to the product of current and voltage. Active power is equal to the average of power over a cycle and is estimated in Watts or by Volt-amperes. Reactive power is that part of power which as zero average value and is estimated in VARs or Voltage-ampere reactive.

\section{REACTIVE POWER CONTROL IN ELECTRICAL SYSTEMS}

In the day-to-day operations, there are both over-voltage and under-voltage violations in the power system which can be controlled by voltage/VAR control. This voltage/VAR control can sustain the voltage profile with permissible range and Lessen the losses in transmission by managing the production, absorption and reactive power flow in each aspect in the system. The flow of reactive power is generally supported by the transmission connected generators. For instance, Grid Code Requirements for the supply of power factor within the range of 0.84 (lagging) to 0.90 (leading) at nominated terminals is done by the use of transmission system generators. A switching operation will be done by the system operator for keeping an assured and sustainable voltage profile at the same time keeping a balanced equation of the reactive power:

Generator - MVARs + System gain + Shunt capacitor $=$ [MVAR - Demand + Reactive losses + Shunt reactors]

The above balance equation has "System Gain" a key source of reactive power, which is produced by the transmission network itself due to its capacitive nature. Before the increase in demand the system gain can be increased like in the early morning when load is less by decisive switching. It helps in securing the system for full day. Some pre-fault reactive generators are needed to balance the equation. Also some other sources for the generation of reactive power are employed like shunt capacitors and reactors, voltage control networks and static VAR compensators.

\subsection{REACTIVE POWER THEORY}

According to the IEEE Standard Dictionary 100-1996 the reactive power is defined as:

\section{REACTIVE POWER $=\sum_{n=1}^{\infty} V_{n} I_{n} \operatorname{Sin}\left(\varphi_{n}\right)$}

Here

$V_{n}=$ rms values of nth harmonics of line frequency of voltage and current.

$\mathrm{I}_{\mathrm{n}}=$ phase difference between voltage and current nth harmonics.
Also, the convention that reactive power must be positive when there is inductive load (current leading voltage) is adopted. The estimation of reactive power is unchallenging and could be achieved easily without errors if the electric system contains entirely sinusoidal voltage and current waveforms at predetermined frequency. However, if there are non-sinusoidal waveforms then errors are present.

As we know, any periodic signal can be represented as aggregate of sine and cosine waves [FOURIER THEOREM]. Since energy meters cope-with periodic signals at the line frequency both the voltage and the current inputs of a single phase meter can be illustrated as:

$$
\begin{aligned}
& \mathrm{V}(\mathrm{t})=\sum_{n=1}^{\infty} \operatorname{Vn} \sqrt{2} \operatorname{Sin}(\mathrm{n} \omega \mathrm{t}) \\
& \mathrm{I}(\mathrm{t})=\sum_{n=1}^{\infty} \operatorname{In} \sqrt{2} \operatorname{Sin}(\mathrm{n} \omega \mathrm{t}+\Phi \mathrm{n})
\end{aligned}
$$

ACTIVE POWER:-

Average real power is explained as

$$
\text { Average real power }=\sum_{n=1}^{\infty} \operatorname{VnInCos}(\varphi)
$$

Its implementation is easy and in most energy meters it is done precisely.

APPARENT POWER:-

The maximum real power supplied/provided to a load is known as apparent power.

$$
\text { Apparent power }=\mathrm{V}_{\text {rms }} \mathrm{I}_{\mathrm{rms}}
$$

$V_{\text {rms }}$ and $I_{r m s}$ are the effective voltages and currents provided to the load respectively. Its implementation is bound by the correctness of the calculation of rms.

\subsection{SIGNIFICANCE OF REACTIVE POWER}

Reactive power controls the voltage in power system. With the increase in reactive power, voltage increases and with the decrease in reactive power, voltage decreases. Voltage control is vital in power system for the functioning of electrical devices, to avert any impairment because of overheating of motors and generators, to lessen the losses in transmission and to manage the capability of the system to resist and avert voltage collapse. The voltage collapse takes place when system is trying to feed a lot more load than the voltage can assist. Just as soon as reactive power lets down voltage, voltage in turn increases the current to keep the power supply constant. This results in more consumption of reactive power by the system which reduces the voltage further. However, if the current exceeds normal range that's if there is a buildup in it, transmission line gets disconnected, and conclusively giving rise to cascading failure by overloading other lines. Also, if voltage drops very much, in order to protect themselves some of the generators go offline automatically. Voltage collapse takes place just as soon as there is increase in load and decrease in voltage, resulting in further decrease in reactive power from capacitors and line charging, which in turn brings further reduction in voltage. As long as voltage keeps decreasing, it will lead to the tripping of additional 
elements, inducing further deduction in voltage and loss of load. This whole unceasing and unmanageable decrease in voltage results in the inability of the system to provide the desired supply (as per demand) of reactive power.

\subsection{EFFECTS OF REACTIVE POWER:-}

Although many electrical appliances require reactive power to run, it has many dangerous effects on appliances and motorized loads. When the amount of current flowing across an electrical system is much more than the required current for doing work, the surplus power is drained in the shape of heat when the reactive currents proceeds across the resistive elements such as transformers, switches and wires. We have to pay every time energy is spent, be it in the form of heat or in the form of any useful work. The calculation of power factor (i.e. ratio between active power and true power) helps us in finding the amount of reactive power our devices are consuming. $100 \%$ power factor (unity power factor) is an ideal case and determines that all the electrical power is administered on the way to the real work. Households usually have power factor between the scales of $75 \%$ to $85 \%$, conditional to the type of electrical device running. However, latest appliances usually in anew homes can have a power factor of about $90 \%$. The usual housing power meter reads only the active power that is the power one can get at unity power factor. Most of the electrical companies don't charge houses precisely for reactive power, but saying that reactive power correction has no economical benefit is just a mere misconception. Nearly all electrical companies gain from the correction of power factor because transmission lines transferring the reactive (additional) current to the greatly commercialized/advanced zones help them in making huge money.

\subsection{REACTIVE POWER AND VOLTAGE CONTROL METHODS:-}

The control of reactive power and voltage necessitate apt harmonization among the reactive power and voltage control appliances in distribution system to get the best reactive power flow and best voltage profile in the system as per the aim function and operating conditions. Power losses can be deduced by choosing appropriate location and size of shunt capacitors. By appropriately choosing the capacitor, voltage profile can be enhanced in the distribution system. The selection of capacitor that's its location and size is interpreted and implemented during the groundwork of distribution system. For further enhancement of distribution system, there should be proper switching of capacitors in the working stage of distribution system by the use of different capacitor controls available. Newly, researchers have directed the issue of control of the reactive power and the voltage in the distribution system by concentrating on the automated distribution system. Based on the automated distribution system, the reactive power and voltage control can be categorized under two types: real time control and offline setting control. Real time controller tries to control capacitor using real time calculations and experiments. Meanwhile, offline setting control tries to forward a scheme for the switching of capacitors. This offline setting control can replace fully the localized control operation of capacitor operations with vaguely control operations. Main disadvantage of this practice is its reliance on communication lines and zapper to all capacitors.

\subsection{WAYS OF IMPROVING VOLTAGE STABILITY} AND CONTROL:-

The ultimate effectual way for the improvement of both voltage stability and capability of power transfer is reactive power compensation. The managing of voltage up to standard scales is achieved by managing the generation, consumption and the flow of reactive power. Since the automatic voltage regulators maintain the field excitation to control the organized voltage levels at the ends of the generator, the primary ways of voltage control are provided by the generating units. For the compensation of reactive power supplementary gadgets are used all over the system for controlling the voltage. Reactive compensation can be classified into shunt and series compensation. It can also be classified into passive and active compensation. Yet mainly thoughts will be concentrated on SVC, STATCOM and shunt capacitor banks. These devices are members of the family of active compensators known as FACTS (Flexible AC Transmission Systems). The appliances that are meant for such motives mentioned above can be categorized as:

- Shunt capacitors

- Series capacitors

- Shunt reactors

- Synchronous condensers

- $\quad$ SVC

- STATCOM

- SHUNT CAPACITORS:-

Passive compensation to a system is provided by shunt and series capacitors. These are either unceasingly attached to a distribution and transmission system or are switched. They add up the voltage control by making alterations in the characteristics of the network. Active compensation is contributed by SVC, STATCOM and Synchronous condensers. These set up voltages at particular points in the system in conjunction with the generating units. The flow of real and reactive power across different elements and even passive compensating devices help in the determination of voltage at other points. The main motive of the shunt compensation in the transmission system just about the load areas is the stabilization of load and voltage control. At substations, for the production of reactive power and control of voltage within specified range, mechanically switched shunt capacitors are set up. For the purpose of voltage stability shunt capacitor banks are very helpful as they tend to keep 
power factor unity in the nearby generators. Mechanically switched capacitor banks have the merit of low cost than the SVCs. However the switching speed of shunt capacitors is quite fast. To reduce the switching transients, use of current limiting reactors is made. However there are certain shortcomings of shunt capacitor banks like in case of voltage emergencies reactive power output drips with the square of voltage. Also, switching isn't fast enough to prevent stalling of induction motor in case of transient voltage instability.
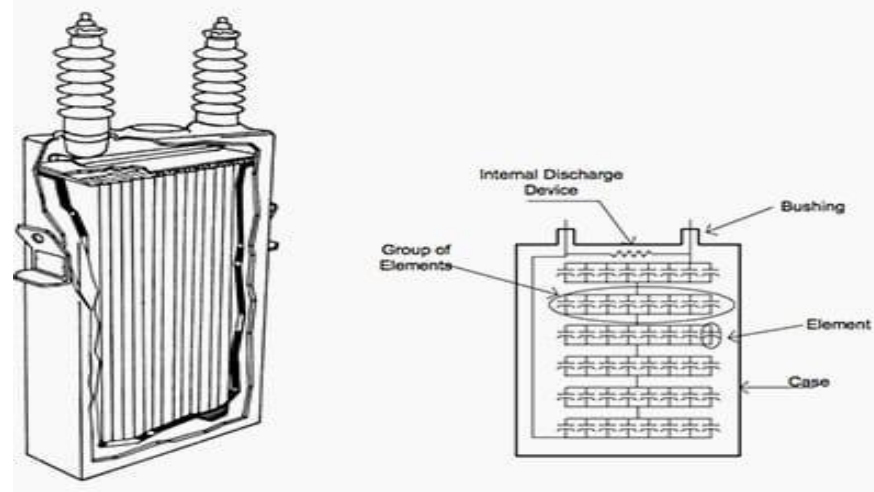

CAPACITOR BANK

\section{- SHUNT REACTORS:-}

Their main purpose is to keep voltage low through the absorption of reactive power for the compensation of capacitive load and whenever there is light load and load rejection in the line.

\section{- SYNCHRONOUS CONDENSERS:-}

The reactive power capacities of synchronous generators and synchronous motors are same. Synchronous condensers are the synchronous machines that are created solely to supply reactive support. These have all the controllability advantages and response speed of generators free from the requirement of building the rest of power plant. They need more maintenance, as these are rotating machines, than the static compensators. These absorb real power equivalent to the reactive power rating of around 3\% of the machine. Synchronous condensers find their applications in transmission systems, chief substations and in harmonization alongside the HVDC Converter Station. Small synchronous generators also find their application in enlarging short circuit power in highpower commercial networks. The yield which is reactive power here is consistently administrable.

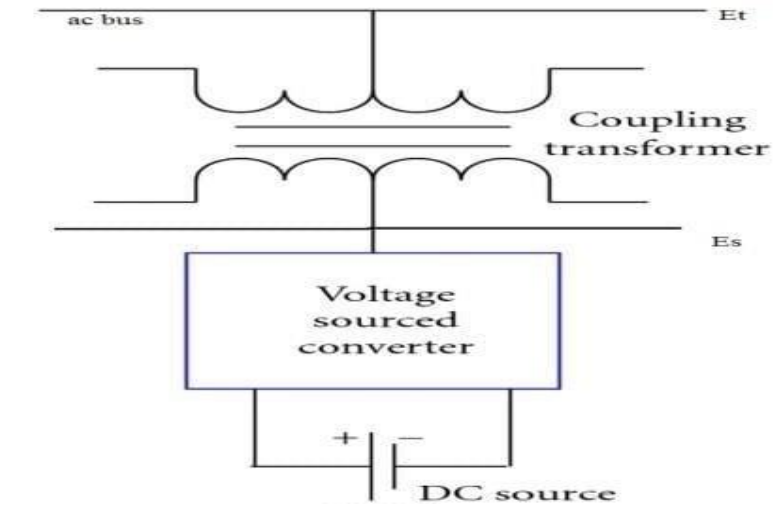

STATIC SYNCHRONOUS COMPENSATOR.

\section{- STATIC VAR COMPENSATORS:-}

SVC merges standard inductors and capacitors with quick switching capacity. Switching supplies consistent range of control as it occurs in sub cycle time frame. The range could be used to develop a span from generating to absorbing reactive power. As SVCs use capacitors they suffer from voltage drop due to reactive capability. Their application needs harmonic filters to lessen the harmonics produced by Thyristor switching. SVCs have a good application in the load areas of low generation as they provide a good control over voltage. It also suffers from the disadvantage as it uses capacitor bank voltage instability occurs there due to voltage collapsing once the capacitor bank reaches its boost limit.

\section{- $\quad$ STATCOM (static synchronous compensator):-}

The solid-state shunt appliance that absorbs or produces reactive power is static synchronous compensator. It is a part of the family of devices called FACTS. It resembles very much with SVC like in the response speed, application of power electronics and control capacities. For the incorporation of reactive power outputs STATCOM utilizes selfcommutated power electronics instead of traditional inductors and capacitors. The controls in STATCOM just like SVC are designed for efficient and quick voltage control. STATCOM magnitude doesn't endure as badly as capacitors and SVCs do by the demeaned voltage as it is not having limited overload capacity of synchronous condensers and generators. The MVAR capability of STATCOMs acknowledges linearly to voltage as they are current limited, which is opposite of the squared voltage relationship of capacitors and SVCs.

\section{- Series Capacitors and Reactors:-}

For the improvement of transient stability and long transmission lines series capacitor compensation is normally tried. Series compensation lessens the overall inductive reactance of the transmission line. The reactive consumption $\left(I^{2} X\right)$ is recompensed by the reactive generation $\left(I^{2} R\right)$ of the 
transmission line $(\mathrm{C})$. When the current is squared it increases the series capacitor reactive generation which generates reactive power when that is most required. Series capacitors have self regulating nature. Series capacitors have little effect at lighter loads.

\subsection{REACTIVE POWER IN POWER SYSTEM FUNCTIONING:-}

Power system operations get affected by reactive power in enormous ways:-

a) There should be a source of reactive as loads consume reactive power.

b) Transformers and transmission lines that constitute delivery system also consume reactive power, so there should be a source to provide that.

c) From supply to the sink, the reactive power flow brings supplementary heating and voltage drop in the lines.

d) Reactive power brings both problems as well as solves the problem of voltage control in the network. If excess reactive power flows in the network it causes overheating and tremendous voltage drop.

\section{CONCLUSION}

In this review paper, reactive power management techniques have been represented that is various aspects of control of voltage and reactive power have been reviewed. Their merits and demerits have been examined. It also describes the situation when our system is heavily loaded and methods by which voltage stability can be improved by injecting reactive power in the system. The major issues in power system networks is the complex interactions between real and reactive power from economic as well as engineering point of view. The forthcoming interrogation is how perfectly and precisely this problem is solved taking into account the dynamic nature of power system.

\section{REFERENCES}

1.K. R. Padiyar, Facts Controllers in Power Transmission and Distribution, New Age International (P) Limited, Publishers, pp. 55-213, 2007.

2.K. Enrique, Acha Claudio, R. Fuerte-Esquivel, Hugo Ambriz-Pérez and César Angeles-Camacho, FACTS Modelling and Simulation in Power Networks, A John Wiley \& Sons, pp. 9-41, 2004.

3.Therese Uzochukwuamaka Okeke and Ramy Georgious Zaher, Reactive Power Management for Distributed Generation: Motivation and Solutions, IEEE, 2013.

4.Fatih Birol, "IEA Renewable Energy Medium Term Market Report 2015" in Executive Director International Energy Agency, Istanbul:G20 Energy Ministerial, October 2015.
5.Desmond O. Ampofo, M.S. Amer Al-Hinai and El Moursi, Utilization of Reactive Power Resources of Distributed Generation for Voltage Collapse Prevention in Optimal Power Flow, IEEE, 2015.

6.T. Aziz, M. J. Hossain, T. K. Saha and N. Mithulananthan, Stability Evaluation of Distributed Generator Integrated System with Index based Placement of STATCOM, IEEE, 2011.

7.Hugo Morais, Tiago Sousa, Pedro Faria and Zita Vale, Reactive Power Management Strategies in Future Smart Grids, IEEE, 2013.

8.S. P. Gawande, Nilesh A. Kubde, Manish S. Joshi and B.S. Sudame, Reactive Power Compensation of Wind Energy Distribution System using Distribution Static Compensator (DSTATCOM), IEEE, 2012.

9.Manju Aggarwal, Prof. S. K. Gupta, Madhusudan and Gaurav Kasal, "D-STATCOM control in Low Voltage Distribution System with Distributed Generation", Third International Conference on Emerging Trends in Engineering and Technology, 2010.

10.Miao-miao Cheng, Daisuke Shiojima, Takanori Isobe and Ryuichi Shimada, "Voltage Control of Induction Generator Powered Distributed System Using a New Reactive Power Compensator SVC-MERS" in EPE-PEMC 2012 ECCE Europe, IEEE, 2012.

11.F. Katiraei and M. R. Iravani, "Power Management Strategies for a Microgrid with Multiple Distributed Generation Units", IEEE Transactions on Power Systems, vol. 21, no. 4, November 2006.

12.H A. Ellis, R. Nelson, E. Von Engeln, R. Walling, J. MacDowell, L. Casey, et al., Reactive Power Performance Requirements for Wind and Solar Plants.

13.D. Gaikwad and S. Mehraeen, Reactive Power Considerations in Reliability Analysis of Photovoltaic Systems, IEEE, 2012.

14. Yong Xue, Jiamei Deng and Shuangbao Ma, "Power Flow Control of a Distributed Generation Unit in Micro-grid" in IPEMC IEEE, 2009.

15.how-reactive-power-is-helpful-to-maintain-a-systemhealthy, [online] Available: http://electrical-engineeringportal.com/how-reactive-power-is-helpful-to-maintain-asystem-healthy.

16.Virginia Tech Education Modules on Distributed Generation, [online] Available: http://www.dg.history.vt.edu/ch1/introduction.html. 17.Renewables topic, [online] Available: http://www.iea.org/topics/renewables/. 